\title{
Coronary Artery Bypass Graft Surgery in Patients on Ticagrelor Therapy Is Not Associated with Adverse Perioperative Outcomes
}

\section{Sammer Diab}

Baruch Padeh Medical Center Poriya

Mattan Arazi

Sheba Hospital: Sheba Medical Center at Tel Hashomer

Leonid Leonid Sternik

Sheba Medical Center at Tel Hashomer

Ehud Raanani Ehud Raanani

Sheba Medical Center at Tel Hashomer

\section{Erez Kachel}

Baruch Padeh Medical Center Poriya

Liza Grosman-Rimon ( $\nabla$ l.grosman.rimon@gmail.com )

Baruch Padeh Medical Center Poriya https://orcid.org/0000-0003-1456-6083

\section{Amjad Shalabi}

Baruch Padeh Medical Center Poriya

Offer Amir Offer Amir

Hadassah Medical Center

\section{Shemy Carasso}

Baruch Padeh Medical Center Poriya

\section{Research article}

Keywords: Ticagrelor, Bleeding, Coronary Artery Bypass Graft Surgery

Posted Date: March 13th, 2021

DOl: https://doi.org/10.21203/rs.3.rs-298467/v1

License: (c) (i) This work is licensed under a Creative Commons Attribution 4.0 International License.

Read Full License 


\section{Abstract \\ Background}

Management of patients treated with ticagrelor is challenging, as stopping Ticagrelor prior to coronary bypass graft surgery (CABG) may increase the risk of acute stent thrombosis. The aim of the study was to compare bleeding complications in patients treated with ticagrelor combined with acetylsalicylic acid (ASA) until one day before surgery versus ASA alone.

\section{Methods}

Bleeding complications, defined as the composite of red blood cells transfusion $\geq 1000 \mathrm{ml}$, chest drainage $\geq 2000 \mathrm{ml}$, and bleeding requiring surgical re-exploration, were compared in 161 patients, 101 on preoperative acetylsalicylic acid (ASA) alone (group A) and 65 on ticagrelor + ASA (group B).

\section{Results}

There were no differences in bleeding complications between the two groups ( $26 \%$ vs. $27 \%$ in group A and $B$, respectively), with similar chest drainage in the first 24 hours $(569 \pm 393 \mathrm{ml}$ and $649 \pm 427 \mathrm{ml}$, respectively).

\section{Conclusions}

Continuing ticagrelor until coronary artery bypass surgery was not associated with increased bleeding complications, suggesting that with appropriate perioperative management, continuing ticagrelor until surgery may be safe.

\section{Introduction}

Acute coronary syndrome (ACS) guidelines recommend that most patients receive dual antiplatelet therapy at the time of presentation to prevent recurrent ischemic events. Approximately $10 \%$ of ACS patients require coronary artery bypass grafting surgery (CABG) (1). Excessive bleeding after cardiac surgery is associated with transfusion of blood products, which is associated with increased morbidity, mortality and high costs (2). One important factor resulting in impaired hemostasis is preoperative use of antithrombotic medications such as platelet inhibitors and anticoagulants (3). Discontinuation of antiplatelet therapy for a time frame prior to surgery that allows recovery of platelet function is warranted $(4-7)$.

However, premature discontinuation of antiplatelet therapy in these settings has been associated with an increase in ischemic complications (8-11) and a reported mortality rate of $25-40 \%$ (12). Indeed, 
ischemic events occur as high as $35.4 \%$ if antiplatelets are discontinued less than 30 days after placement of a coronary drug eluting stent, and decline to $11.7 \%$ if discontinued later but within the first 6 months, with a reported mortality rate of $25-40 \%$ (13) Ticagrelor is an oral, reversibly binding and directly acting P2Y12 receptor antagonist that rapidly peaks within 1.5-3 hours, has a rapid onset of antiplatelet effects, and half-life of 7 to 8 hours. Furthermore, this reversibility may offer great flexibility for surgical procedures (14). The optimal discontinuation time of P2Y12 antagonists before CABG is still poorly defined. Data regarding the true incidence of bleeding with shorter discontinuation periods of P2Y12 antagonists are lacking. Continuing ticagrelor to less than 2 days prior to surgery or at time of surgery was associated with a 3.5 times higher risk of platelet transfusions compared to patients receiving aspirin alone, while an increased rate of severe bleeding was noted in patients receiving ticagrelor one day before or just before surgery (15-18). Hansson et al (19) reported data from the SWEDEHEART registry on CABG-related bleeding complications in ACS patients on dual anti-platelet therapy (DAPT). The authors demonstrated that in contrast to clopidogrel, discontinuation of ticagrelor 3 days before surgery, as opposed to 5 days, did not increase the incidence of major bleeding (20). In the PLATO trial, ticagrelor treatment was recommended to be withheld for $1-3$ days before CABG $(21,22)$. Current guidelines recommend that dual antiplatelet therapy be withheld at least three days prior to surgery (23, 24).

Management of patients treated with ticagrelor is challenging, and currently there is no effective therapeutic option. The aim of the present study was to investigate the safety of cardiac surgery when ticagrelor combined with acetylsalicylic acid (ASA) were continued to one day before surgery compared to ASA alone.

\section{Methods}

A retrospective, observational study was performed to evaluate perioperative bleeding complications associated with recent Ticagrelor therapy in patients who underwent CABG. In total 161 consecutive patients underwent isolated CABG or CABG/Valvular procedures in the Cardiovascular Department at Poriya Medical Center, Tiberias, Israel. Data was collected from the departmental clinical registry.

The registry and study were approved by our hospital ethics review board.

Patients were divided into two groups: patients preoperatively receiving ticagrelor + acetylsalicylic acid (ASA) (group $A, n=55$ ) or ASA alone (group $B, N=106$ ) until cardiac surgery.

Data on peri-operative events from admission to discharge were collected. We assessed postoperative blood loss volume during the first and second postoperative days. This was defined by the total chest tube drainage. The indications for surgical re-exploration were chest blood loss $>400 \mathrm{ml}$ over the first hour, $>300 \mathrm{ml}$ for two consecutive hours or $>200 \mathrm{ml}$ for four consecutive hours. The primary end point was defined as the composite of red blood cells (RBCs) transfusion $\geq 1000 \mathrm{ml}$, chest drainage $\geq 2000 \mathrm{ml}$ and bleeding requiring surgical re-exploration (16). We also compared the incidence and number of allogeneic blood products (plasma and platelets) transfused during the index hospital stay. 
Surgical technique and postoperative management were standardized for all patients. All patients underwent on-pump CABG. A median sternotomy followed by cardiopulmonary bypass was instituted with the use of ascending aortic cannulation and two-stage venous cannulation of the right atrium. The membrane oxygenator was primed with $1000 \mathrm{ml}$ of Hartmann's crystalloid, $500 \mathrm{ml}$ gelofusine, $0.5 \mathrm{~g} / \mathrm{kg}$ mannitol, $7 \mathrm{ml}$ of $10 \%$ calcium gluconate and $6000 \mathrm{IU}$ heparin. Alpha-stat pH management was used, and the systemic temperature was kept between 32 and $36^{\circ} \mathrm{C}$. Myocardial protection was achieved with intermittent hyperkalaemic cold blood cardioplegia.

At the end of surgery, patients were transferred to the intensive care unit. Values of prothrombin time, activated partial thromboplastin time and international normalized ratio of $>1.5$ times control were corrected with fresh frozen plasma. A platelet count $<60,000 / \mu \mathrm{l}$ was an indicator for platelet transfusion. A haemoglobin $<8 \mathrm{~g} / \mathrm{dl}$ was the threshold for transfusion of red blood cells. According to unit policy, patients received ASA $300 \mathrm{mg}$ suppository per gastric tube within $6 \mathrm{~h}$ after surgery; in case of bleedings, antiplatelet treatment was delayed to the day after.

\section{Statistical analysis}

Based on the $\sim 20 \%$ incidence of major bleeding complications in patients treated with dual antiplatelets stopped after 72 hrs prior to surgery (16), we needed a patients sample size of 93 to detect a significant doubling of its incidence (type I error $p<0.05$, type II error $<0.1$ ).

Categorical variables were expressed as percentages and continuous variables as means \pm standard deviations. Subgroups were compared using the Wilcoxon-Mann-Whitney non-parametric test or independent t-test as appropriate. Chi-Square analysis was used for categorical variables. Statistical significance was defined as a $p$ value $<0.05$. Multivariable logistic regression analysis was performed to assess the association between age, smoking, number of coronary stents in situ, preoperative ACEi/ARBs, hemoglobin and use of ticagrelor with major bleeding complications. Statistical analyses were performed using MedCalc Statistical Software version 15.6.1 (MedCalc Software bvba, Ostend, Belgium).

\section{Results}

In total, we included 161 patients who underwent CABG in our hospital. The patients were divided into two groups: patients preoperatively receiving acetylsalicylic alone (group $A, N=106$ ) and patients receiving ticagrelor + ASA (group $B, n=55$ ), with the last dose in both groups given the day before surgery.

Baseline data are presented in Table 1. Baseline parameters showed no significant difference between the two groups. There were no differences in sex, most cardiac risk factors and preoperative medications. Notably, patients on pre-operative anticoagulants were not treated by aspirin. Patients in Groups B were 5 years younger than patients in group A. Current smoking was also more prevalent in Group B. Patients in group $B$ had twice as many previous coronary interventions with coronary stents in situ as patients in group A. A greater percentage of patients in group B used an Angiotensin Converting Enzyme Inhibitor (ACEi) or Angiotensin Receptor Blocker (ARB), Table 1. Both groups had the same euro and syntax score. 
Pre-operative LV systolic function was similar among both groups. Patients on dual anti-platelet therapy (group B) had $0.5 \mathrm{gr} / \mathrm{dl}$ significantly lower pre-operative hemoglobin level compared to patients on ASA alone (group $A),(P=0.025$, Table 2$)$.

The two groups were balanced with regard to surgery characteristics (Table 3). Nearly all patients received a left internal mammary arterial graft in addition to receiving 2.3 to 2.5 grafts; concomitant valve surgery was significantly more prevalent in the ASA alone group, mainly due to increased aortic valve surgery. Mean cardiopulmonary bypass time was not different between the groups.

Table 4 shows the outcome data in this study. Patients in group B had a 13 hour shorter stay in the intensive care unit post-operatively. However, both groups had similar mechanical ventilation time and rate of intra-aortic balloon pump usage. Length of hospital stay was similar between the two groups.

The primary end point composite of major bleeding complications (RBC infusion of $\geq 1000 \mathrm{ml}$, chest drainage $\geq 2000 \mathrm{ml}$ or bleeding requiring surgical re-exploration) was found in just above a quarter of patients in both groups (table 4). The incidence of major bleeding complications remained unchanged after exclusion of 20 patients that had concomitant valve surgery. Regarding blood loss, there was a small yet significantly lower hemoglobin threshold treated by ASA + ticagrelor compared to patients treated with ASA alone.

Hemoglobin change from baseline was similar in both groups as was the post-operative utilization of blood products (red blood cells, fresh frozen plasma, platelets and cryoprecipitate). Total and Postoperative day 1 pleural/pericardial chest drainage volumes were similar as well.

In multivariable logistic regression analysis that included age, smoking, number of coronary stents in situ, preoperative ACEi/ARBs, hemoglobin and use of ticagrelor, only higher hemoglobin levels was found to be associated with reduction of major bleeding complications $(\mathrm{HR}=0.73, \mathrm{Cl} 0.55-0.97, \mathrm{p}=0.0246)$.

Non-Bleeding post-surgical complications were similar in both groups except for atrial fibrillation, the prevalence of which was significantly lower in group B. None of the patients had stent thrombosis. No patients in either group underwent surgical re-exploration for a major bleeding complication.

\section{Discussion}

Many patients needing coronary surgical revascularization have significant left main disease or multivessel coronary disease. DAPT is usually prescribed in these patients after diagnostic coronary angiography, $\mathrm{PCl}$ and/or stent implantation pending surgical revascularization (25). Yet, the optimal discontinuation time of $\mathrm{P} 2 \mathrm{Y} 12$ antagonists prior to $\mathrm{CABG}$ is poorly defined. Current guidelines recommend holding the drug for at least 3 days for ticagrelor or 7 days for prasugrel prior to surgery ( 9 , $23,24)$. However, this may not be a realistic option in every case, as discontinuation of DAPT may actually increase the risk of stent thrombosis complicating the perioperative course. Several studies have shown that administration of ticagrelor prior to cardiac surgery, especially in combination with ASA, may 
increase the risk of postoperative bleeding, resulting in increased administration of blood products, rethoracotomies and lengthening of post-operative hospital stay (15-18). In a sub-study of the PLATO trial, ticagrelor was stopped 24-72 hours prior to CABG surgery (26). The authors demonstrated that the total and cardiovascular mortality decreased without an increased risk of bleeding. However another study where ticagrelor continued until the last day prior to surgery demonstrated a clear trend towards a higher incidence of major bleeding (27).

A recent systematic review (28) summarized the updated guidelines for perioperative DAPT treatment in patients who are candidates for CABG surgery. The guidelines discussed provide differing recommendations, which may lead to a lack of standardization in clinical practice. Overall, the authors classify their recommendations based on the urgency of surgery performed.

For the elective patients, most guidelines recommend that aspirin be continued while clopidogrel and ticagrelor should be discontinued at least 5 days before surgery, and prasagruel one week prior. A few recent sources advise stopping ticagrelor 3 days prior to surgery (29-31), which was supported by a patient cohort that demonstrated no increase in major bleeding complications (19). In regards to the urgent $C A B G$, various guidelines recommend discontinuing dual antiplatelet therapy between 24-72 hours prior to surgery $(5,28,32-35)$. However, ESC 2015 (4) and TSC 2018 (30) propose that the urgent CABG could be performed regardless of their continuation. Therefore, the consequences of delaying an urgent surgery due to an increased risk of bleeding compared to early discontinuation of DAPT is still under debate (28). Following CABG, antiplatelet therapy is recommended in post-stent patients to help prevent graft occlusion and stent thrombosis for 12 months or 1-12 months depending on risk of thrombosis $(4,5,29-31)$. Overall, due to the discrepancy between guideline recommendations, more evidence is required to standardize the perioperative management of DAPT in CABG patients.

In this study, we observed whether patients undergoing CABG under continued preoperative use of ticagrelor + ASA differs from patients under ASA alone. Patients treated with ASA + ticagrelor were 3 years younger, were more currently smoking and had twice as many had coronary stents in situ compared to patients treated with ASA alone prior to surgery, probably establishing the reason for DAPT in these patients. However, pre-operative left ventricular systolic function and risk scores were comparable in both groups, as were the surgical interventions added to CABG and over all pump times, establishing that the two groups could actually be compared. Post-operatively, both groups showed similar bleeding parameters, including maximal hemoglobin drop, utilization of blood products, and day 1 and total chest drainage volumes. Complication rates were also similar and no patients had a stent thrombosis.

This study shows that among patients initially treated for ACS with antiplatelets that subsequently underwent CABG, ticagrelor + ASA compared with ASA alone was not associated with risk of CABGrelated bleeding. This observation suggests that it may be safe to operate without discontinuation of ticagrelor for at least 5 days prior to surgery as currently recommended in guidelines; however, future studies are needed to further evaluate the risk of CABG-related bleeding under recent ticagrelor therapy. 


\section{Study Limitations}

This was a single center retrospective study in a special setting of a fully combined cardiologycardiovascular surgery service. Our surgeons were not blinded to pre-operative treatment and probably anticipated and reacted to bleeding during surgery, which may have led to improved hemostatic treatment in the DAPT group. This practice of meticulous hemostasis in DAPT treated patients has probably contributed to the comparable outcomes in both groups. Indeed, this actually represents a real-life situation, and is probably the recommended way to approach and operate on patients treated by DAPT that require surgical revascularization.

\section{Conclusion}

Continuing ticagrelor until surgery did not increase the risk of bleeding complications after CABG compared with patients on ASA alone. The overall risk of CABG related bleeding complications was the same in ticagrelor + ASA group compared ASA alone group in this observational study. Although patients on dual therapy are known to be at increased risk, with appropriate perioperative management, continuing ticagrelor until surgery may be safe provided that the surgeons are aware of its administration. Future studies are warranted to investigate the risk of CABG-related bleeding under recent ticagrelor therapy.

\section{Abbreviations}

ASA - acetylsalicylic acid

ACS - Acute coronary syndrome

CABG - Coronary artery bypass graft (surgery)

CAD - Coronary artery disease

COPD - Chronic obstructive pulmonary disease

DAPT - Dual anti platelet therapy

\section{Declarations}

This study was approved by the ethics committee of Poriya Medical Center. All patients signed a concent form to participate in the study.

\section{Consent for publication}

A consent was obtained from each patient participating in the study.

\section{Availability of data and materials}


Please contact the authors for data requests.

\section{Competing interests}

The authors declare that they have no competing interests.

\section{Funding}

No funding was received.

\section{Authors' contributions}

All authors contributed to the manuscript and met the criteria for authorship.

\section{Author contributions}

Diab Sammer: Concept/design, Data analysis/interpretation, drafting article,

Leonid Sternik: Critical revision of article.

Ehud Raanani: Critical revision of article

Erez Kachel: Critical revision of article, Approval of article

Liza Grosman-Rimon: Drafting the paper, Critical revision of the paper

Mattan Aazi: Drafting the paper, Critical revision of the paper

Amjad shalabi: Data collection, Critical revision of article.

Offer Amir: Critical revision of article, Approval of article

Shemy Carasso: Concept/design, Data analysis/interpretation, drafting article.

\section{Acknowledgements}

Not applicable

\section{References}

1. Gielen CL, Bruggemans EF, Stijnen T et al. Stopping antiplatelet medication before coronary artery bypass graft surgery: Is there an optimal timing to minimize bleeding? Eur J Cardiothorac Surg 2015;48(4):e64-70.

2. Hamm CW, Bassand JP, Agewall S et al. Esc guidelines for the management of acute coronary syndromes in patients presenting without persistent st-segment elevation: The task force for the 
management of acute coronary syndromes (acs) in patients presenting without persistent stsegment elevation of the european society of cardiology (esc). Eur Heart J 2011;32(23):2999-3054.

3. Angiolillo DJ, Firstenberg MS, Price MJ et al. Bridging antiplatelet therapy with cangrelor in patients undergoing cardiac surgery: A randomized controlled trial. JAMA 2012;307(3):265-274.

4. Roffi M, Patrono C, Collet JP et al. 2015 esc guidelines for the management of acute coronary syndromes in patients presenting without persistent st-segment elevation: Task force for the management of acute coronary syndromes in patients presenting without persistent st-segment elevation of the european society of cardiology (esc). Eur Heart J 2016;37(3):267-315.

5. Amsterdam EA, Wenger NK, Brindis RG et al. 2014 aha/acc guideline for the management of patients with non-st-elevation acute coronary syndromes: A report of the american college of cardiology/american heart association task force on practice guidelines. J Am Coll Cardiol 2014;64(24):e139-e228.

6. Montalescot G, van 't Hof AW. Prehospital ticagrelor in st-segment elevation myocardial infarction. N Engl J Med 2014;371(24):2339.

7. Subiakto I, Asrar ul Haq M, Van Gaal WJ. Bleeding risk and incidence in real world percutaneous coronary intervention patients with ticagrelor. Heart Lung Circ 2015;24(4):404-406.

8. Hansson EC, Rexius H, Dellborg M, Albertsson P, Jeppsson A. Coronary artery bypass grafting-related bleeding complications in real-life acute coronary syndrome patients treated with clopidogrel or ticagrelor. Eur J Cardiothorac Surg 2014;46(4):699-705; discussion 705.

9. DiNicolantonio JJ, D'Ascenzo F, Tomek A, Chatterjee S, Niazi AK, Biondi-Zoccai G. Clopidogrel is safer than ticagrelor in regard to bleeds: A closer look at the plato trial. Int J Cardiol 2013;168(3):17391744.

10. Bonhomme F, Fontana P, Reny JL. How to manage prasugrel and ticagrelor in daily practice. Eur J Intern Med 2014;25(3):213-220.

11. Held C, Asenblad N, Bassand JP et al. Ticagrelor versus clopidogrel in patients with acute coronary syndromes undergoing coronary artery bypass surgery: Results from the plato (platelet inhibition and patient outcomes) trial. J Am Coll Cardiol 2011;57(6):672-684.

12. Spertus JA, Kettelkamp R, Vance $C$ et al. Prevalence, predictors, and outcomes of premature discontinuation of thienopyridine therapy after drug-eluting stent placement: Results from the premier registry. Circulation 2006;113(24):2803-2809.

13. Zwart B, Godschalk TC, Kelder JC, Ten Berg JM. High risk of stent thrombosis in the first 6 months after coronary stenting: Do not discontinue clopidogrel early after acs. J Interv Cardiol 2017;30(5):421-426.

14. Vivacqua A, Koch CG, Yousuf AM et al. Morbidity of bleeding after cardiac surgery: Is it blood transfusion, reoperation for bleeding, or both? Ann Thorac Surg 2011;91(6):1780-1790.

15. Fitchett $D$, Eikelboom J, Fremes $S$ et al. Dual antiplatelet therapy in patients requiring urgent coronary artery bypass grafting surgery: A position statement of the canadian cardiovascular society. Can $\mathrm{J}$ Cardiol 2009;25(12):683-689. 
16. Kremke M, Gissel MS, Jensen MJ, Thomassen SA, Jakobsen CJ. The association between a threeday ticagrelor discontinuation and perioperative bleeding complications. Eur J Cardiothorac Surg 2019;55(4):714-720.

17. Malm CJ, Hansson EC, Akesson J et al. Preoperative platelet function predicts perioperative bleeding complications in ticagrelor-treated cardiac surgery patients: A prospective observational study. $\mathrm{Br} \mathrm{J}$ Anaesth 2016;117(3):309-315.

18. Tomsic A, Schotborgh MA, Manshanden JS, Li WW, de Mol BA. Coronary artery bypass graftingrelated bleeding complications in patients treated with dual antiplatelet treatment. Eur $\mathrm{J}$ Cardiothorac Surg 2016;50(5):849-856.

19. Hansson EC, Jideus $L$, Aberg $B$ et al. Coronary artery bypass grafting-related bleeding complications in patients treated with ticagrelor or clopidogrel: A nationwide study. Eur Heart J 2016;37(2):189-197.

20. Weidinger F. Discontinuation of p2y12 antagonists before coronary bypass surgery: Is 5 days really required? Eur Heart J 2016;37(2):198-199.

21. Kushner FG, Hand M, Smith SC, Jr. et al. 2009 focused updates: Acc/aha guidelines for the management of patients with st-elevation myocardial infarction (updating the 2004 guideline and 2007 focused update) and acc/aha/scai guidelines on percutaneous coronary intervention (updating the 2005 guideline and 2007 focused update) a report of the american college of cardiology foundation/american heart association task force on practice guidelines. J Am Coll Cardiol 2009;54(23):2205-2241.

22. Miceli A, Duggan SM, Aresu G et al. Combined clopidogrel and aspirin treatment up to surgery increases the risk of postoperative myocardial infarction, blood loss and reoperation for bleeding in patients undergoing coronary artery bypass grafting. Eur J Cardiothorac Surg 2013;43(4):722-728.

23. Valgimigli M, Bueno H, Byrne RA et al. 2017 esc focused update on dual antiplatelet therapy in coronary artery disease developed in collaboration with eacts: The task force for dual antiplatelet therapy in coronary artery disease of the european society of cardiology (esc) and of the european association for cardio-thoracic surgery (eacts). Eur Heart J 2018;39(3):213-260.

24. Sousa-Uva M, Head SJ, Milojevic M et al. 2017 eacts guidelines on perioperative medication in adult cardiac surgery. Eur J Cardiothorac Surg 2018;53(1):5-33.

25. Schaefer A, Sill B, Schoenebeck J et al. Preoperative ticagrelor administration leads to a higher risk of bleeding during and after coronary bypass surgery in a case-matched analysis. Interact Cardiovasc Thorac Surg 2016;22(2):136-140.

26. Mehta SR, Yusuf S. The clopidogrel in unstable angina to prevent recurrent events (cure) trial programme; rationale, design and baseline characteristics including a meta-analysis of the effects of thienopyridines in vascular disease. Eur Heart J 2000;21(24):2033-2041.

27. Hillis LD, Smith PK, Anderson JL et al. 2011 accf/aha guideline for coronary artery bypass graft surgery. A report of the american college of cardiology foundation/american heart association task force on practice guidelines. Developed in collaboration with the american association for thoracic 
surgery, society of cardiovascular anesthesiologists, and society of thoracic surgeons. J Am Coll Cardiol 2011;58(24):e123-210.

28. Zhang ZZ, Zhang SZ, Zhou HM et al. A systematic review of guidelines for dual antiplatelet therapy in coronary artery bypass graft. European journal of clinical investigation 2021;51(1):e13405.

29. Neumann FJ, Sousa-Uva M, Ahlsson A et al. 2018 esc/eacts guidelines on myocardial revascularization. Eur Heart J 2019;40(2):87-165.

30. Li YH, Wang YC, Wang YC et al. 2018 guidelines of the taiwan society of cardiology, taiwan society of emergency medicine and taiwan society of cardiovascular interventions for the management of non st-segment elevation acute coronary syndrome. Journal of the Formosan Medical Association = Taiwan yi zhi 2018;117(9):766-790.

31. Nakamura M, Kimura K, Kimura T et al. Jcs 2020 guideline focused update on antithrombotic therapy in patients with coronary artery disease. Circ J 2020;84(5):831-865.

32. Hillis LD, Smith PK, Anderson JL et al. 2011 accf/aha guideline for coronary artery bypass graft surgery: Executive summary: A report of the american college of cardiology foundation/american heart association task force on practice guidelines. Circulation 2011;124(23):2610-2642.

33. Ferraris VA, Saha SP, Oestreich JH et al. 2012 update to the society of thoracic surgeons guideline on use of antiplatelet drugs in patients having cardiac and noncardiac operations. Ann Thorac Surg 2012;94(5):1761-1781.

34. O'Gara PT, Kushner FG, Ascheim DD et al. 2013 accf/aha guideline for the management of stelevation myocardial infarction: A report of the american college of cardiology foundation/american heart association task force on practice guidelines. Circulation 2013;127(4):e362-425.

35. Mehta SR, Bainey KR, Cantor WJ et al. 2018 canadian cardiovascular society/canadian association of interventional cardiology focused update of the guidelines for the use of antiplatelet therapy. Can J Cardiol 2018;34(3):214-233.

\section{Tables}

Table 1 Preoperative baseline data of study group and control group 


\begin{tabular}{|c|c|c|c|}
\hline & $\begin{array}{l}\text { Group A } \\
\text { ASA alone } \\
n=106(\%)\end{array}$ & $\begin{array}{l}\text { Group B } \\
\text { Ticagrelor +ASA } \\
n=55(\%)\end{array}$ & p-Value \\
\hline Age (years) & $64 \pm 8$ & $61 \pm 10$ & 0.034 \\
\hline Sex, Male $(n, \%)$ & $92(87)$ & $53(69)$ & 0.092 \\
\hline $\begin{array}{l}\text { Risk profile } \\
\text { Diabetes Mellitus }\end{array}$ & $45(42)$ & $26(47)$ & 0.622 \\
\hline Hypertension & $75(71)$ & $42(76)$ & 0.461 \\
\hline Hyperlipidemia & $80(75)$ & $42(76)$ & 0.850 \\
\hline Smoking, current & $40(38)$ & $30(54)$ & 0.002 \\
\hline Smoking, past & $13(12)$ & $3(5)$ & 0.267 \\
\hline Obesity & $17(16)$ & $14(25)$ & 0.207 \\
\hline Previous CAD & $38(36)$ & $22(40)$ & 0.733 \\
\hline Coronary stents in situ & $28(26)$ & $25(51)$ & 0.003 \\
\hline Paroxysmal atrial fibrillation & $7(7)$ & $1(2)$ & 0.054 \\
\hline Renal Failure & $3(3)$ & $3(5)$ & 0.414 \\
\hline Congestive heart failure & $19(18)$ & $7(13)$ & 0.500 \\
\hline Peripheral vascular disease & $7(7)$ & $1(2)$ & 0.265 \\
\hline Cerebrovascular accident & $6(6)$ & $5(9)$ & 0.514 \\
\hline COPD & $6(6)$ & $2(5)$ & 0.716 \\
\hline $\begin{array}{l}\text { Medications } \\
\text { Aspirin }\end{array}$ & $97(92)$ & $54(98)$ & 0.137 \\
\hline Anticoagulant therapy (any) & $7(7)$ & $1(2)$ & 0.254 \\
\hline ACEi/ARB & $51(48)$ & $38(61)$ & 0.002 \\
\hline$\beta$ Blockers & $76(72)$ & $47(85)$ & 0.085 \\
\hline Calcium Channel Blockers & $28(26)$ & $15(27)$ & 0.854 \\
\hline
\end{tabular}

CAD: Coronary artery disease; ASA: acetylsalicylic acid; COPD: chronic obstructive pulmonary disease; ACE: angiotensin-converting enzyme; 
Table 2 Pre-operative status

\begin{tabular}{|llll|}
\hline & $\begin{array}{l}\text { Group A } \\
\text { ASA alone }\end{array}$ & $\begin{array}{l}\text { Group B } \\
\text { Ticagrelor +ASA }\end{array}$ & p-Value \\
& $\mathbf{n}=106$ & $\mathbf{n}=55$ & \\
\hline Euroscore & $2 \% \pm 2$ & $3 \% \pm 2$ & 0.729 \\
\hline Syntax Score & $28.7 \pm 9.8$ & $28.9 \pm 8.8$ & 0.602 \\
\hline LV ejection fraction $(\%)$ & $54 \pm 11$ & $55 \pm 11$ & 0.884 \\
\hline Hemoglobin $(\mathrm{gr} / \mathrm{dl})$ & $11.3 \pm 1.4$ & $10.8 \pm 1.5$ & 0.025 \\
\hline
\end{tabular}

EuroSCORE: European System for Cardiac Operative Risk Evaluation;

SYNTAX: score is a grading system that evaluates the complexity and prognosis of patients undergoing percutaneous coronary intervention (PCl)

LVEF: left ventricular ejection fraction; NYHA: New York Heart Association.

Table 3 Surgery characteristics

\begin{tabular}{|llll|}
\hline & $\begin{array}{l}\text { Group A } \\
\text { ASA alone }\end{array}$ & $\begin{array}{l}\text { Group B } \\
\text { Ticagrelor +ASA }\end{array}$ & p-Value \\
& $\mathbf{n = 1 0 6 ( \% )}$ & $\mathbf{n = 5 5 ( \% )}$ & \\
\hline Coronary Artery Bypass graft & $105(99)$ & $55(100)$ & NS \\
\hline LIMA & $104(98)$ & $55(100)$ & NS \\
\hline No. of Grafts & $2.3 \pm 0.9$ & $2.5 \pm 0.8$ & 0.345 \\
\hline Concomitant valve surgery $(\mathrm{n}, \%)$ & $19(18)$ & $1(2)$ & 0.001 \\
& & & \\
\hline Aortic valve & $12(11)$ & $0(0)$ & 0.01 \\
\hline Mitral valve & $9(8)$ & $1(2)$ & NS \\
\hline Tricuspid valve & $2(1)$ & $0(0)$ & NS \\
\hline Temperature $\left(^{\circ}\right.$ Celsius) & $36.0 \pm 0.7$ & $36.1 \pm 0.7$ & 0.732 \\
\hline Pump time (minutes) & $105 \pm 41$ & $102 \pm 36$ & 0.250 \\
\hline
\end{tabular}

LIMA: left internal mammary artery 
Table 4 Outcome data

Page 14/16 


\begin{tabular}{|c|c|c|c|}
\hline & $\begin{array}{l}\text { Group A } \\
\text { ASA alone } \\
n=106(\%)\end{array}$ & $\begin{array}{l}\text { Group B } \\
\text { Ticagrelor +ASA } \\
n=55(\%)\end{array}$ & $\mathrm{p}$-Value \\
\hline Time in intensive care unit (hrs) & $93 \pm 70$ & $70 \pm 24$ & 0.005 \\
\hline Ventilation time (hrs) & $13 \pm 13$ & $15 \pm 16$ & 0.990 \\
\hline Intraaortic balloon pump (n, \%) & $2(2)$ & $2(4)$ & 0.608 \\
\hline Post operative discharge day & $8.3 \pm 8.1$ & $7.3 \pm 4.6$ & 0.552 \\
\hline Lowest Hemoglobin (gr/dl) & $8.6 \pm 1.2$ & $8.4 \pm 0.9$ & 0.028 \\
\hline$\Delta$ Hemoglobin $(\mathrm{gr} / \mathrm{dl})$ & $2.7 \pm 1.3$ & $2.5 \pm 1.3$ & 0.804 \\
\hline $\begin{array}{l}\text { Chest drainage volume (ml) } \\
\text { Day } 1\end{array}$ & $569 \pm 393$ & $649 \pm 427$ & 0.854 \\
\hline Total volume & $1477 \pm 1012$ & $1454 \pm 715$ & 0.086 \\
\hline $\begin{array}{l}\text { Blood products infused (units) } \\
\text { Red blood packed cells }\end{array}$ & $1.2 \pm 1.6$ & $1.3 \pm 1.3$ & 0.576 \\
\hline Fresh frozen plasma & $0.5 \pm 1.2$ & $0.4 \pm 1$ & 0.112 \\
\hline Cryoprecipitate & $0.2 \pm 1.4$ & $0.1 \pm 0.8$ & 0.420 \\
\hline Platelets & $2.3 \pm 3.8$ & $2.4 \pm 3.4$ & 0.547 \\
\hline $\begin{array}{l}\text { Complications }(n, \%) \\
\text { Bleeding requiring surgical re-ex }\end{array}$ & 0 & 0 & NS \\
\hline Neurologic (incl. stroke) & $1(1)$ & $0(0)$ & NS \\
\hline Pneumonia & $4(4)$ & $3(5)$ & 0.692 \\
\hline Infection (any) & $5(5)$ & $5(10)$ & 0.316 \\
\hline Renal failure & $10(10)$ & $1(2)$ & 0.099 \\
\hline Requiring dialysis & 0 & 0 & NS \\
\hline Discharged with dialysis & 0 & 0 & NS \\
\hline Atrial fibrillation & $40(38)$ & $12(22)$ & 0.035 \\
\hline Permanent pacemaker & $0(0)$ & $1(2)$ & NS \\
\hline Gastrointestinal & 0 & 0 & NS \\
\hline Primary End Point & $28(26)$ & $15(27)$ & NS \\
\hline
\end{tabular}


| (RBC>1000cc, drainage $\geq 2000 c c$, or Revision)

Values are given as mean+SD

Page 16/16 